\title{
Increased levels of ethane, a non-invasive, quantitative, direct marker of $n-3$ lipid peroxidation, in the breath of patients with schizophrenia
}

\author{
Basant K Puri ${ }^{1 *}$, Brian M Ross ${ }^{2}$, lan $\mathrm{H}_{\text {Treasaden }}{ }^{3}$ \\ From $1^{\text {st }}$ International Congress on Neurobiology and Clinical Psychopharmacology and \\ European Psychiatric Association Conference on Treatment Guidance \\ Thessaloniki, Greece. 19-22 November 2009
}

\section{Background}

This study directly assessed whether there was a change in the level of exhaled ethane, which provides a noninvasive, quantitative, direct measure of n-3 lipid peroxidation, in the breath of patients with schizophrenia.

\section{Materials and methods}

Samples of alveolar air were obtained from 20 subjects with schizophrenia and 23 age- and sex-matched healthy control subjects. The air samples were analyzed for ethane using mass spectrometry.

\section{Results}

The mean level of ethane in the schizophrenia sample (5.15 (S.E. 0.56) ppb) was significantly higher than that of the healthy controls (2.63 (S.E. 0.31) ppb; p < 0.0005). A further sub-analysis showed that nicotine dependence was unlikely to be the cause of this difference.

\section{Conclusions}

These results suggest that the measurement of exhaled ethane levels may offer a non-invasive direct marker of increased n-3 lipid peroxidation in schizophrenia.

\section{Author details}

'Imaging Sciences Department, Hammersmith Hospital, Imperial College London, UK. ${ }^{2}$ Division of Medical Sciences, Northern Ontario School of Medicine, Lakehead University, Ontario, Canada. ${ }^{3}$ Head of Forensic

Neurosciences, Lipid Neuroscience Group, Imperial College London and

'Imaging Sciences Department, Hammersmith Hospital, Imperial College London, UK

(0) 2009 Puri et al; licensee BioMed Central Ltd.
Three Bridges Medium Secure Unit, West London Mental Health NHS Trust, Middlesex, UK.

Published: 22 April 2010

doi:10.1186/1744-859X-9-S1-S150

Cite this article as: Puri et al:: Increased levels of ethane, a non-invasive, quantitative, direct marker of $\mathrm{n}-3$ lipid peroxidation, in the breath of patients with schizophrenia. Annals of General Psychiatry 2010 9(Suppl 1): S150.

Submit your next manuscript to BioMed Central and take full advantage of:

- Convenient online submission

- Thorough peer review

- No space constraints or color figure charges

- Immediate publication on acceptance

- Inclusion in PubMed, CAS, Scopus and Google Scholar

- Research which is freely available for redistribution 